\title{
Longitudinal evaluation of the impact of traditional rainbow trout farming on receiving water quality in Ireland
}

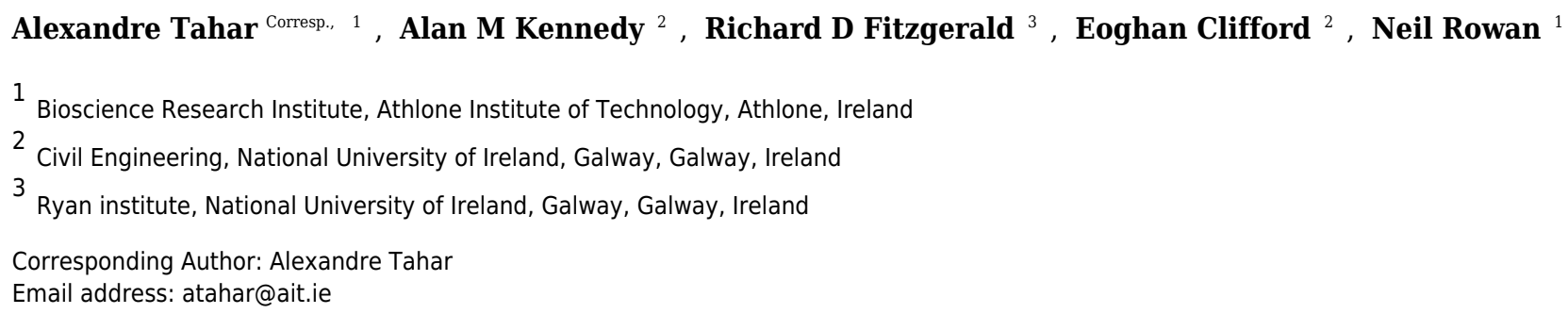

In the context of future aquaculture intensification, a longitudinal 10-years evaluation of the current traditional rainbow trout production in Ireland was performed. Publically available and independent data obtained from local authorities were gathered and analysed. Inlet and outlet concentrations of parameters such as $\mathrm{BOD}_{5}$, ammonium, nitrite, dissolved oxygen and $\mathrm{pH}$ for 4 consecutive flow-through fish farms covering the 4 seasons over a 10 years period (2005-2015) were analysed. The objectives of the study were (i) to characterize the impact of each fish farm on water quality in function of their respective production and identify any seasonal variability, (ii) to quantify the cumulative impact of the four farms on the river quality and to check if the self-purification capacity of the river was enough to allow the river to reach back its background levels for the analysed parameters, (iii) to build a baseline study for Ireland in order to extrapolate as a dataset for expected climate change and production intensification. For most of the parameter analysed no significant impact of the fish farming activity on water quality/river quality was observed. These results, the first ones generated in Ireland so far, will have to be completed by a survey on biodiversity and ecotoxicology and compared after production intensification and the likely future introduction of water treatment systems on the different sites. 


\section{Longitudinal evaluation of the impact of traditional rainbow trout}

\section{2 farming on receiving water quality in Ireland}

3 Alexandre Tahar $^{(1)^{*}}$, Alan M. Kennedy ${ }^{(2)}$, Richard D. Fitzgerald ${ }^{(3)}$, Eoghan Clifford ${ }^{(2)}$, Neil Rowan ${ }^{(1)}$

4

5 (1) Athlone Institute of Technology (AIT), Dublin Road, Athlone, Co. Westmeath, Ireland

6 (2) Civil Engineering, College of Engineering and Informatics, NUI Galway, Galway, Ireland

7 (3) Ryan institute, NUI Galway, Galway, Ireland

8

9

10 Corresponding author:

11 Alexandre Tahar ${ }^{(1)}$

12 Corresponding e-mail address:

13 atahar@ait.ie 


\section{Abstract}

19 In the context of future aquaculture intensification, a longitudinal 10 -years evaluation of the current traditional rainbow trout production in Ireland was performed. Publically available and independent data obtained from local authorities were gathered and analysed. Inlet and outlet concentrations of parameters such as $\mathrm{BOD}_{5}$, ammonium, nitrite, dissolved oxygen and $\mathrm{pH}$ for 4 consecutive flow-through fish farms covering the 4 seasons over a 10 years period (2005-2015) were analysed. The objectives of the study were (i) to characterize the impact of each fish farm on water quality in function of their respective production and identify any seasonal variability, (ii) to quantify the cumulative impact of the four farms on the river quality and to check if the self-purification capacity of the river was enough to allow the river to reach back its background levels for the analysed parameters, (iii) to build a baseline study for Ireland in order to extrapolate as a dataset for expected climate change and production intensification. For most of the parameter analysed no significant impact of the fish farming activity on water quality/river quality was observed. These results, the first ones generated in Ireland so far, will have to be completed by a survey on biodiversity and ecotoxicology and compared after production intensification and the likely future introduction of water treatment systems on the different sites. 


\section{Introduction}

37 With the wild fish catching capacities almost reached and the overall human population increase on the

38 planet, fish from aquaculture is and will increasingly become a more important food source for human consumption in a near future (e.g. Donnely 2011; Guilpart et al. 2012). Aquaculture production increased more than five-fold from 1990 to 2012 while the world capture fisheries increased with only $8 \%$ at the same time (Krause et al. 2015). Furthermore, it is planned that this increase in production will be sharper in the next decades in Ireland with notably the objective of increasing food export (including aquaculture fish products) by $85 \%$ by 2025 through the application of the Food Wise 2025, the strategic plan for the development of agri-food sector (DAFM 2015). The future and current intensification of this activity is associated with meeting more stringent environmental regulations to ensure a sustainable and environmentally friendly production. At European scale, freshwater fish farming is essentially regulated through the Water framework directive (WFD) that aims at providing good chemical and ecological status of the rivers (Aubin et al. 2011; EC 2000; Guilpart et al. 2012). Currently, there is a dearth in scientific knowledge on the potential impact and environmental risk of aquaculture farming practices on receiving water quality as it relates to both WFD compliance and related EU Rivers Basin Management Plan 2016-

512021.

Various anthropogenic activities can cause the deterioration of river quality including point source pollution such as wastewater treatment plants (WWTPs) with the discharge of partially treated effluents or non-point sources such as agricultural activities (e.g. Papatryphon et al. 2005). The traditional freshwater fish farming industry generally operates using flow-through systems (FT) without any water treatment, with the oxygen levels being maintained by relatively high volume water abstraction \& flow

57 through the farm. Fish farming activity generates wastes from fish excreta and uneaten feed which if 
et al. 2014; Garcia et al. 2014; Lalonde et al. 2015; Lazzari \& Baldisserotto 2008; Sindilariu et al. 2009; Verdegem 2013). The potential impacts of such intensive FT fish farming on receiving river quality can include increased concentrations of 5-day biochemical oxygen demand $\left(\mathrm{BOD}_{5}\right)$, a drop in dissolved oxygen concentrations (DO), an enrichment of total suspended solids (TSS) content in the receiving water, in nutrients such as nitrogen generally characterised by total ammonia nitrogen (TAN), and phosphorus generally characterised by orthophosphate $\left(\mathrm{PO}_{4}-\mathrm{P}\right)$ that could both potentially lead to surface water eutrophication (e.g. Boaventura et al. 1997; Caramel et al. 2014; Garcia et al. 2014; Lazzari \& Baldisserotto 2008; Teodorowicz 2013). This impact will depend on the production system employed, the production intensity and on the type of feed but also on the assimilative capacity of the receiving water (Boaventura et al. 1997; Caramel et al. 2014).

A number of studies have focused on the characterization of freshwater fish farm effluents across the world (e.g. Boaventura et al. 1997; Guilpart et al. 2012; Lalonde et al. 2015; Neto et al. 2015; True et al. 2004). Most of these studies have inherent drawbacks due to their respective framework; some studies focused only on a short period of time of one year or less (e.g. Caramel et al. 2014; Všetičková et al. 2012; Živić et al. 2009) or relied on individual water samples (e.g. Caramel et al. 2014; Hennessy et al. 1996; Lalonde et al. 2015; Noroozrajabi et al. 2013; Všetičková et al. 2012), while the impact of aquaculture should be assessed using longer term evaluation process encompassing production, fish life stages and river characteristics variations (Aubin et al. 2011; Hennessy et al. 1996). Other studies (e.g. Koçer et al. 2013; Sindilariu et al. 2009; Všetičková et al. 2012; Yalcuk et al. 2014) have focused on fish farm gates (comparison of farm inlet and outlet water quality) and did not aim at evaluating the impact they might have on receiving water. Some limited studies (Aubin et al. 2011; Boaventura et al. 1997; Pulatsu et al. 2004) analysed the impact of freshwater fish farming on the receiving water quality during a long period of time (i.e. at least two years duration) allowing to fully understand the impact of specific farms on specific rivers and in specific places. However, data from these studies are difficult to extrapolate and 
83 apply into different contexts in light of the parameters and conditions such as species, temperature,

84 aquaculture practices, chemicals used, receiving water features (e.g. flow, hydromorphology) and local environmental conditions that may be very specific to individual farms and locations (Lalonde et al. 2015).

With the increasing demand for fish and fish products worldwide (e.g. Guilpart et al. 2012), the freshwater aquaculture industry is facing the challenge of finding the way to produce more without any associated environmental degradation (Martins et al. 2010; Sturrock et al. 2008; Teodorowicz 2013). In some countries such as Denmark, freshwater aquaculture practices have recently evolved to model trout farms, systems that were able to fulfil both production and environmental objectives (Jokumsen \& Svendsen 2010; Lalonde et al. 2015; Teodorowicz 2013). However, some other countries such as Poland (Teodorowicz 2013), France (Papatryphon et al. 2005) and Ireland still require a drastic evolution of the aquaculture practices through more advanced systems in order to fulfil those ambitious objectives. To the best of our knowledge, there is no existing data about the impact of freshwater fish farming on downstream river quality in Ireland. There is therefore a pressing need to evaluate the impact of aquaculture activity on a longer-term basis using evidence-based data that are publically available, and to ascertain if there is any accumulation of pollution in receiving water. Thus, the main aim of the present study was to evaluate such data in terms of reported aquaculture influent and effluent parameters over a 10 years period in order to establish relationship (if any) with receiving water quality in Ireland. In that aim, the impact of 4 consecutive FT traditional freshwater rainbow trout (Oncorhynchus mykiss) farms on the receiving water quality was assessed through publically available historical data analysis (2005-2015).

102 The objectives of the study were (i) to characterize the impact of each fish farm on water quality in 103 function of their respective production and identify any seasonal variability, (ii) to quantify the cumulative 104 impact of the 4 farms on the river quality and to check if the self-purification capacity of the river was 
106 baseline study for Ireland in order to extrapolate as a dataset for expected climate change and production

107 intensification.

108

109

\section{Materials and methods}

\section{Fish farms description}

111 The studied facilities are all Irish traditional rainbow trout fish farms, all operating in a FT system during

112 the studied period. The schematic fish farms representation below (Figure 1), shows the very specific 113 configuration of the area with 4 different farms, all abstracting the water needed and having their 114 discharge into the same river, all in a relative small area (about $4 \mathrm{~km}$ between the first and the last farm). 115 This specific configuration allowed the study of the potential cumulative impact the fish farms might have 116 on river quality.

Farm 1 (F1) was a hatchery and juvenile (i.e. $<100$ g) production site. It was operating in FT in a concrete channel separated in different consecutive sections and had a partial recirculation of the water associated

122 to an oxygenation step (no water treatment). As a hatchery site, this farm was the most sensitive to water 123 quality and this is why it was historically located at the most upstream location where the water quality 124 was not theoretically affected by the fish farm activity yet. Farm 2 (F2) was at about $2 \mathrm{~km}$ downstream 125 from F1 and was a medium size (i.e. 100-500 g) on-growing site that was operating in FT in an earthen 126 pond. Farm 3 (F3) was at about 1.5km downstream from F2 and was an on-growing site (i.e. $500 \mathrm{~g}$ to 
127 harvest size) that was operating in FT in earthen ponds with a partial recirculation of the water associated

128 to oxygenation (no water treatment). Farm 4 (F4) was at about 500m downstream from F3 and was an

129 on-growing site (i.e. $500 \mathrm{~g}$ to harvest size) that was operating in FT in an earthen pond associated to a

130 sedimentation pond aiming at removing settleable solids from the discharge water.

131 On average the 4 farms produced 75, 50, 165 and 100 tons a year respectively during the investigated 132 period (2005-2015).

133 Considering that there was no or limited form of water treatment on these farms (Figure 1), the objective 134 was to evaluate the impact of the whole pool of farms, and of successive individual farms, on the water 135 quality in order to check if there was any accumulation of pollution (e.g. TSS, $\mathrm{BOD}_{5}, \mathrm{TAN}, \mathrm{PO}_{4}-\mathrm{P}$ ) within 136 their receiving water. According to www.epa.ie/hydronet/\#Water\%20Levels, the river 95\% percentile 137 flow was calculated as being $1.1 \mathrm{~m}^{3} / \mathrm{s}$ (average over 30 years of $5.5 \mathrm{~m}^{3} / \mathrm{s}$ ). It is noteworthy that there was no agricultural activity or WWTPs within the area (i.e. upstream and in between the different farms) and that therefore, in the present study, any significant modification of the river quality downstream from the farms will be attributed to the fish farming activity and will represent its impact on the river quality.

141 The farms water intake flow was measured at regular intervals by the fish farmer and were about $0.4 \mathrm{~m}^{3} / \mathrm{s}$ on average on each farm (range $0.1-0.6 \mathrm{~m}^{3} / \mathrm{s}$ depending on the farm and the flow conditions in the river).

\section{The discharge licence}

Each Irish County Council (Local Authority) require two licences to operate - an aquaculture licence issued by the Department of Agriculture, Food \& the Marine and a Trade Effluent Discharge Licence issued by the relevant Local Authority. 
148 For these 4 farms the discharge licences states both (i) a regulation on the maximum water abstraction

149 rate that the farm cannot exceed depending on the river flow, and (ii) a maximum differential 150 concentration (or value) between fish farms influent and effluent waters for a range of parameters (i.e. 1

$151 \mathrm{mgO}_{2} / \mathrm{L}$ for $\mathrm{BOD}_{5}, 10 \mathrm{mg} / \mathrm{L}$ for TSS, $5 \mathrm{NTU}$ for turbidity, $0.4 \mathrm{mgN} / \mathrm{L}$ for TAN, $0.002 \mathrm{mgN} / \mathrm{L}$ for nitrite $\left(\mathrm{NO}_{2^{-}}\right.$

$152 \mathrm{~N}$ ) and $0.2 \mathrm{mgP} / \mathrm{L}$ for $\mathrm{PO}_{4}-\mathrm{P}$ ). For three other parameters, the regulation defines absolute limit values for 153 the farm effluent (i.e. $60 \%$ saturation for $\mathrm{DO}$, range 6-9 for $\mathrm{pH}$ and ambient temperature). The discharge 154 licence specified that each fish farm had to be sampled by the regulatory agency for both inlet and outlet 155 water at a frequency of 4 times a year (i.e. generally one sampling per season).

The parameters monitored

A full 10-year record of historical data (2005-2015) generated by an independent and accredited water analysis lab was gathered for this study. The present study focused on the parameters that were monitored and analysed during the studied period. Hence regulated parameters (presented in the previous section) and total oxidised nitrogen (TON), representing the sum of $\mathrm{NO}_{2}-\mathrm{N}$ and nitrate $\left(\mathrm{NO}_{3}-\mathrm{N}\right)$, were considered for the present study. $\left(\mathrm{NH}_{4}-\mathrm{N}\right)$ was monitored instead of TAN (regulated parameter) that represents the sum of $\mathrm{NH}_{4}-\mathrm{N}$ and ammonia $\left(\mathrm{NH}_{3}-\mathrm{N}\right)$, the latter being much more toxic for fish (Tomasso 1994). The predominance of one ammonia form or another depends on $\mathrm{pH}$ and temperature with $\mathrm{NH}_{3}-\mathrm{N}$ predominating at high temperature and $\mathrm{pH}$ values (Emerson et al. 1975). Therefore, for the present study, $\mathrm{pH}$ and temperature values were used to enable an estimation of TAN concentrations from $\mathrm{NH}_{4}-\mathrm{N}$ measurements. analysis of each monitored parameter. 


\section{Sampling}

173 All samples were performed as spot samples and no composite samples were taken. According to the

174 Local Authority responsible for the water monitoring, all the inlet sampling locations ( $\mathrm{i}_{1-4}$, see Figure 1 )

175 were located in the river itself immediately upstream from the inlet channel of each farm (taken every 176 time at the same section at the centre of the river). The outlet sampling spots $\left(0_{1-4}\right.$, see Figure 1$)$ were 177 directly located in the outlet channels of each farm (farm effluents) and therefore do not include any 178 dilution by the downstream river.

179 The discharge licence did not specify a sampling method and thus it is likely that spot samples were 180 employed as they were considered the most efficient and cheap sampling method. Samples (i.e. $1 \mathrm{~L}$ in PET 181 bottles) were stabilized in acidic conditions (to reach a $\mathrm{pH}$ value below 2 in order to avoid any 182 transformation of the nitrogenous compounds) and brought to the labs where they were kept refrigerated 183 before analysis. Dissolved oxygen saturation levels, $\mathrm{pH}$ and temperature values were obtained in-situ 184 before sample stabilization by a multi-parameter sensor (YSI 51B oxygenmeter and WTW pH $330 \mathrm{pH}$ 185 meter). Separate samples were taken for the analysis of $\mathrm{BOD}_{5}$ parameter (not acidified).

\section{Approach employed for the quantification of the fish farms impacts}

The following range of assessments were considered when evaluating the impacts of the farms on the receiving river water - individual farm impact on water quality, and cumulative impact of the 4 fish farms on river water quality. Additionally, in order to check a potential higher impact during summer condition

191 (as observed in Lalonde et al. 2015), the seasonal variability of the impacts was also studied by considering 192 the evolution of the effluents quality and the impacts for the different seasons all along the year. For this 
193

194 195 196

purpose, data obtained from a monitoring in December, January and February were classified as "winter data"; the ones from the months of March, April and May as "spring data"; the ones from the months of June, July and August as "summer data" and the ones from the months of September, October and November as "autumn data".

As discussed above, the 4 fish farms were abstracting the water from and discharging into the same river (Figure 1). Therefore the fish farms inlet analysis results (i.e. $I_{1}, I_{2}, I_{3}$ and $I_{4}$ ) were employed to study the evolution of the water quality along the river across the 4 farms. We notice that this method was used to study the impact of the three first farms (i.e. farms 1-3). The evaluation of the cumulative impact of the 3 first farms (F1, F2 and F3) on the river quality was achieved by the comparison of the results obtained in $i_{1}$ and $i_{4}$ sampling locations. This allowed to take account of the dilution of the effluent of each farm by the river and therefore to take account of the pollution load emitted by the farms. The impact of F4 was not possible to assess this way because river quality downstream from this farm was not monitored (i.e. the only location of these farm effluent monitoring points that does not take account of the dilution by the river, see Figure 1).

Unfortunately, those results were not correlated to the fish parameters because we could not have access to accurate records of these biological data but only average yearly production. Therefore, this study only focused on water quality parameters.

\section{Data treatment}

The following equation was used to calculate the differential concentrations $\left(D_{i}\right)$ for each monitored farm (i) and parameter introduced above.

$D_{i}=O_{i}-I_{i}$ 
215 With $\mathrm{O}_{\mathrm{i}}$ and $\mathrm{I}_{\mathrm{i}}$ the outlet and inlet concentrations at the farm $\mathrm{i}$ for a given parameter on a given sampling 216 event.

Only concentration values were considered and treated although load values (taking farm outlet flow values in consideration) would have been a better way to characterize the impact of the different farms. However, flow values were not measured continuously on the different sites and this did not allow for an accurate calculation of the loads for the different parameters at different times. Plus river concentrations were employed to characterize the impact of the different farms on river quality; those river concentrations are taking river dilution into account and were therefore considered as a good approach to consider the load of each of parameters considered.

Statistical tests were performed using Matlab software in order to assess if datasets means were significantly different (e.g. concentrations measured upstream and downstream from each farm) and if the fish farms had an impact on the water quality. Box plot representations of the data were chosen in order to show the dispersion of the data and to avoid any misinterpretation due to the occurrence of extreme values. Two samples Student's t-tests were employed to compare datasets after checking the normal distribution of each dataset (validity domain of this statistical test). A confidence interval of $95 \%$ was systematically employed.

Many results from the datasets obtained from the regulation body were below the limit of quantification

233 (LOQ) associated to the analytical method employed. In this case, for the calculations performed in the present study and because the sampling and analysis were not performed by our team, the data was considered as equal to the LOQ (substitution approach). The real value of the data could be lower than 
237 could have been used such as "below LOQ = LOQ/2" or "below LOQ = LOQ/V2" (Hornund \& Reed 1990;

238 USEPA 2003), to avoid any misinterpretations.

\section{Results and discussion}

\section{General overview of the results - Outcome of inlet and outlet values for each parameters}

242 More than 1,000 inlet/outlet couples of data were gathered overall for all the parameters and the 4 fish

243 farms investigated. The full dataset as well as the representation of the data for each parameter and each

244 farm and the monthly distribution of the data are presented in supplementary materials sections (SP1,

245 Table S1, Table S2).

The figure below (Figure 2) gives an overview of the gathered data for all farms and presents a global comparison of inlet and outlet water quality observed globally and for all the parameters monitored. mean increase or decrease of the monitored parameters values caused by the 4 farms without distinction. No significant differences between farms inlets and outlets was observed for TON, temperature, $\mathrm{BOD}_{5}$, turbidity, TSS and $\mathrm{NO}_{2}-\mathrm{N}(\mathrm{P}$ value $>0.05)$ demonstrating that the investigated fish farms might have no

257 inlets to outlets was observed for $\mathrm{NH}_{4}-\mathrm{N}(\mathrm{P}$ value $<0.001), \mathrm{PO}_{4}-\mathrm{P}(\mathrm{P}$ value $<0.001)$ and $\mathrm{BOD}_{5}(\mathrm{P}$ value $<$ 
258 0.01) demonstrating that the investigated fish farms might have an impact on the downstream river

259 quality through the release of those compounds. However, the increase in $\mathrm{NH}_{4}-\mathrm{N}$ was of only about 0.08

$260 \mathrm{mgN} / \mathrm{L}$ on average ( $\pm 0.08 \mathrm{mgN} / \mathrm{L}, \mathrm{n}=130$, see Figure $2 \mathrm{~F}$ ) that can be considered as a relatively low value

261 compared to values found in other studies such as $1.46 \mathrm{mgN} / \mathrm{L}$ increase (Boaventura et al. 1997). The

262 same observation can be done for $\mathrm{PO}_{4}-\mathrm{P}$ with an average increase of about $0.015 \mathrm{mgP} / \mathrm{L}( \pm 0.03 \mathrm{mgP} / \mathrm{L}$,

$263 \mathrm{n}=130$, see Figure $2 \mathrm{G}$ ) found in the present study and a range of $0.06-0.58 \mathrm{mgP} / \mathrm{L}$ increase found in

264 another study where three different rainbow trout farms were investigated during one year (Boaventura

265 et al. 1997). Some other studies observed some increase from rainbow trout farms inlets to outlets for

$266 \mathrm{NH}_{4}-\mathrm{N}$ (Caramel et al. 2014; Guilpart et al. 2012; Kırkağaç et al. 2009; Lalonde et al. 2015), BOD

267 (Teodorowicz 2013), total nitrogen (Caramel et al. 2014; Lalonde et al. 2015), total phosphorus (Caramel

268 et al. 2014; Kırkağaç et al. 2009; Lalonde et al. 2015) and $\mathrm{PO}_{4}-\mathrm{P}$ (Caramel et al. 2014; Guilpart et al. 2012).

269 Furthermore, a significant decrease was observed in the present study at fish farms outlet compared to

270 inlets for both $\mathrm{DO}(\mathrm{P}$ value $<0.001)$ and $\mathrm{pH}(\mathrm{P}$ value $=0.001)$ showing, as expected, $(\mathrm{i})$ a global oxygen

271 consumption due to fish metabolism (Boyd \& Tucker 1998), and (ii) a production of carbon dioxide by fish

272 with the consequence of lower pH value at the outlets (Boyd \& Tucker 1998). An average decrease in DO

273 of about $1.42 \mathrm{mgO}_{2} / \mathrm{L}\left( \pm 1.28 \mathrm{mgO}_{2} / \mathrm{L}, \mathrm{n}=101\right.$, see Figure $2 \mathrm{l}$ ) from farms inlets to farms outlets was

274 observed, that is in agreement with previously published results such as a study where a DO decrease of

$2750.7-2.4 \mathrm{mgO}_{2} / \mathrm{L}$ depending on the fish farm investigated was found (Boaventura et al. 1997). A deeper

276 focus on these data with an emphasis on inlet and outlet of each farm will be presented in the following

277 sections of this study to whether or not confirm these global trends. An evaluation of potential significant

278 impacts of those individual fish farms on the receiving water quality for the monitored parameters will be 279 given. 
281 Impact on water quality - individual farms level

282 The objective of this section are (i) to quantify the impact of each farm on water quality and (ii) to address

283 their compliance to their discharge licences criteria.

Parameters regulated in term of differential concentrations

286

287

288

289

290

291

292

293

294

295

296

297

298

299

300

301

302

Below, is presented an outcome of the differential concentrations for 5 regulated parameters (i.e. $\mathrm{BOD}_{5}$, $\mathrm{NO}_{2}-\mathrm{N}, \mathrm{PO}_{4}-\mathrm{P}$, TSS and turbidity) and for ammonium $\left(\mathrm{NH}_{4}-\mathrm{N}\right)$ for each farm (Figure 3).

\section{INSERT FIGURE 3}

A first general observation of the results is that for most of the regulated parameters (i.e. turbidity, TSS, $\mathrm{PO}_{4}-\mathrm{P}, \mathrm{NH}_{4}-\mathrm{N}, \mathrm{BOD}_{5}$ ) neither the average nor median values are higher than their associated differential limit value. The different farms were therefore globally in compliance with their discharge licence for those parameters. An exception is $\mathrm{NO}_{2}-\mathrm{N}$ with an average differential concentration higher than the limit value (i.e. $0.006 \pm 0.025 \mathrm{mgN} / \mathrm{L}, \mathrm{n}=40$ vs $0.002 \mathrm{mgN} / \mathrm{L}$, see Figure $3 \mathrm{C}$ ) for F4. However, the median value was equal to the limit value (i.e. $0.002 \mathrm{mgN} / \mathrm{L}$ ) underpinning the influence of extreme values on the average calculation. For this parameter, a large number of data were $<\mathrm{LOQ}$ and as stated above were considered as equal to the LOQ; for F1 a very large proportion of the data (i.e. about 95\%) were < LOQ at both inlet and outlet giving resulting differential concentrations of $0 \mathrm{mgN} / \mathrm{L}$ according to the equation presented in the materials and method section (it is noticed that the same result would have been obtained with a different choice of values for analysis below the LOQ). Surprisingly the LOQ for $\mathrm{NO}_{2}-\mathrm{N}$ was generally $0.06 \mathrm{mgN} / \mathrm{L}$ which is higher than the differential concentration limit of $0.002 \mathrm{mgN} / \mathrm{L}$. This shows 
303 the limit of the approach set by the Local Authority to set some very low differential limits that cannot

304 actually be addressed by the chemical analysis procedure typically applied in accredited chemical analysis 305 labs.

306 For $\mathrm{BOD}_{5}$, a global compliance with the discharge licence was observed with both average and median 307 values below the differential limit value (i.e. $1 \mathrm{mgO}_{2} / \mathrm{L}$, see Figure 3B) for the 4 farms. However, for F2, F3 308 and F4 a substantial number of individual differentials values was above the limit value (i.e. about a quarter of the values for the three farms) demonstrating that even if a general compliance was observed the compliance was not achieved all the time. The low differential limit value for this parameter (i.e. 1 $\mathrm{mgO}_{2} / \mathrm{L}$ ) compared to other fish farms in the country (i.e. generally $2 \mathrm{mg} / \mathrm{L}$ ) might explain this relative high number of "non-compliance" data. Furthermore, according to the statistical analysis performed, no significant difference were observed between the different farms for $\mathrm{BOD}_{5}$ differential values (i.e. P values $314>0.05)$.

For TAN (i.e. $\mathrm{NH}_{4}-\mathrm{N}+\mathrm{NH}_{3}-\mathrm{N}$ ), the compliance cannot be directly assessed by the available $\mathrm{NH}_{4}-\mathrm{N}$ monitoring; however, considering that $\mathrm{pH}$ values were always below 8 (i.e. range $6.5-7.5 \mathrm{pH}$ units, see supplementary material SP1) and the temperature range of $5-15^{\circ} \mathrm{C}$ during all the monitoring period (see supplementary material SP1), $\mathrm{NH}_{4}-\mathrm{N}$ was highly predominating over $\mathrm{NH}_{3}-\mathrm{N}$ and therefore TAN concentrations were similar to $\mathrm{NH}_{4}-\mathrm{N}$ (about $0.1 \mathrm{mgN} / \mathrm{L}$ depending on the farm, see Figure 3F). Therefore the conclusion is that all farms were in compliance with the differential concentration limit for TAN of 0.4 $\mathrm{mgN} / \mathrm{L}$. Furthermore, according to the statistical analysis performed, some significant differences were

322 observed between the different farms in terms of $\mathrm{NH}_{4}-\mathrm{N}$ differential values; mean $\mathrm{NH}_{4}-\mathrm{N}$ differential value for F1 was revealed to be significantly lower than for F2 ( $P$ value $>0.05), F 3(P$ value $<0.001)$ and F4 ( $P$

324 value $<0.01$ ). No significant difference was observed between F2, F3 and F4 for this parameter. 
325 Farm 2 and F4 showed a substantial proportion of negative differential values for turbidity and TSS (i.e.

326 nearly half of the total number of data for these farms, see Figure 3E) demonstrating that those farms

327 were polishing the water regarding solids. The earthen pond configuration and low water velocity for F2

328 and the presence of a sedimentation pond in F4 could explain this observation (Figure 1). However, the

329 presence of such solid removal processes did not enhance the removal of other compounds such as BOD

330 and $\mathrm{PO}_{4}-\mathrm{P}$ that could have been reduced by the presence of a sedimentation pond (Teodorowicz 2013).

331 The statistical analysis of the data showed that the TSS differential mean value was significantly lower for

332 F2 than for F3 ( $P$ value < 0.01). No other significant difference between farms was observed for both TSS

333 and turbidity.

334 Farm 3 was the farm with the highest average yearly production of 165 tons (Figure 1) and was also the 335 one associated to the highest average differential values for $\mathrm{PO}_{4}-\mathrm{P}$ and $\mathrm{NH}_{4}-\mathrm{N}$

336 (i.e. $0.02 \pm 0.042 \mathrm{mgP} / \mathrm{L}, \mathrm{n}=42$ and $0.1 \pm 0.08 \mathrm{mgN} / \mathrm{L}, \mathrm{n}=42$, respectively, see Figure $3 \mathrm{D}$ and $3 \mathrm{~F}$ ), even if the difference with the other farms were not significant according to the statistical analysis. In the present study, a higher fish production led to a higher release of phosphorus and nitrogenous wastes as was observed in other studies such as Guilpart et al (2012) where a proportionality relationship was observed between nutrient release and farm production. For the same set of parameters, F1 was revealed to be less impacting than the other farms with on average lower differential values than any other farm. This might be due to a relative low yearly production in this farm (i.e. 75 tons, see Figure 1 ) and the fact that this was a hatchery and juvenile production farm as it was observed in another study (Guilpart et al. 2012; Teodorowicz 2013). The statistical analysis revealed that mean $\mathrm{PO}_{4}-\mathrm{P}$ differential value for $\mathrm{F} 1$ was significantly lower than for F3 ( $P$ value $=0.01)$ and for F4 $(P$ value $<0.001)$. No other significant difference between the different farms was observed for $\mathrm{PO}_{4}-\mathrm{P}$.

347 Globally, a general compliance with the discharge licence for all the regulated parameters was observed 348 for the 4 farms and that therefore the studied individual fish farms were not substantially impacting water 
349 quality. However, it was also observed that the F3 and F4 had on average higher differential values than

350 the other farms. This fact could be due to higher yearly production for F3 and F4 compared to the other

351 farms (Figure 1) (Boaventura et al. 1997; Guilpart et al. 2012; Teodorowicz 2013).

352

353

\section{Parameters regulated in term of absolute values}

354 Three parameters were regulated in term of absolute effluent values (i.e. DO, pH, temperature). The limit

355 value for DO was $60 \%$ saturation in water and it appeared in the present study that no value was found

356 to be below this threshold (average value for all farm outlets of $80 \%$ saturation, see supplementary

357 materials SP1). The accepted range for $\mathrm{pH}$ was 6-9 $\mathrm{pH}$ units and no value was found to be out of this range

358 with an actual range of 6.5-7.5 pH units for all farms (see supplementary materials SP1). For temperature,

359 the discharge licence stated that the effluent had to be "ambient" and no significant differences were

360 observed between farms inlets and outlets (see supplementary materials SP1) meaning that the outlet

361 water was actually at ambient temperature. Therefore the 4 different farms were in compliance with the

362 discharge licence for these three parameters and the farms were not substantially impacting water quality

363 for these parameters.

364

The statistical analysis revealed that for temperature, the mean differential value for F3 was significantly

365

higher than for F4 ( $P$ value $<0.05)$. This could be due to the different configuration of those farms; F3 being

a multi-pond based farm with an assumed (not measured) associated relatively high hydraulic retention time (HRT), allowing a higher water heating potential than F4 which was assumed to be associated to a lower HRT due to its different configuration (i.e. only two ponds) and therefore a lower heating potential reveal any significant differences between the 4 farms. 


\section{Cumulative impact of the fish farms on the river quality}

373 The evolution of the quality of the inlet water through the 4 consecutive fish farms is presented on the

374 figure below (Figure 4).

375

376

INSERT FIGURE 4

377

378

Upstream water quality

379

Background river quality (i.e. $l_{1}$, see Figure 4 ) was on average very suitable for rainbow trout production

with temperature range of $5-15^{\circ} \mathrm{C}$ (see supplementary materials SP1), high level of DO (i.e. about $10.3 \pm$

$1.29 \mathrm{mgO}_{2} / \mathrm{L}, \mathrm{n}=17$ on average, see Figure $4 \mathrm{G}$ ), low levels of $\mathrm{BOD}_{5}$ (i.e. about $2.06 \pm 0.95 \mathrm{mgO} / \mathrm{L}, \mathrm{n}=17$ on

average, see Figure 4B), $\mathrm{NH}_{4}-\mathrm{N}$ (i.e. $0.08 \pm 0.004 \mathrm{mgN} / \mathrm{L}, \mathrm{n}=17$ on average, see Figure 4D), $\mathrm{NO}_{2}-\mathrm{N}$ (i.e. 0.06

$\pm 0.012 \mathrm{mgN} / \mathrm{L}, \mathrm{n}=17$ on average, see Figure $4 \mathrm{H}$ ) and TON (i.e. $1.36 \pm 0.32 \mathrm{mgN} / \mathrm{L}, \mathrm{n}=16$ on average, see

Figure 4A). Overall, these levels are all suitable for fish growth and all below the proven chronic toxicity

levels for salmonids (EEC 1978). Furthermore, these values confirmed that there was no potentially

386

polluting activity (e.g. agriculture, WWTP) upstream from the fish farms that would have degraded the river quality for the parameters monitored.

$\mathrm{BOD}_{5} /$ dissolved oxygen (DO) patterns through the river flow

390

Overall there was no negative impact observed on river water quality due to the farms in terms of $\mathrm{BOD}_{5}$

391

and DO concentrations which remained at about $2 \mathrm{mgO}_{2} / \mathrm{L}$ and $10 \mathrm{mgO}_{2} / \mathrm{L}$ respectively across the 4 392 different farms inlets and therefore along the river. 
393 For DO, these results demonstrated that even if a significant decrease was observed at farm scale (as

394 mentioned before), the river had the potential to reoxygenate between the different farms to reach its

395 background level. In a similar study dealing with the cumulative impact of 5 different rainbow trout farms

396 in Turkey, Pulatsu et al (2004) observed an impact of fish farming that significantly decreased the DO levels

397 in the river at $100 \mathrm{~m}$ downstream from the last farm. This relative short distance compared to distances

398 between the different farms in the present study might explain why an impact was observed in this study.

399 For $\mathrm{BOD}_{5}$, no significant difference in the inlet mean concentrations for the 4 farms was observed in the

400 present study according to the statistical test applied ( $P$ value $>0.05$ ) (Figure 4B). This demonstrated that

401 even if some $\mathrm{BOD}_{5}$ differential concentrations were higher than the limit values for F2, F3 and F4, this had

402 globally no impact on the river quality. Some possible explanation for this observed trend could be a

403 combination of (i) a relative high river flow compared to average fish farms water uptake flow providing

404 a high dilution capacity to the river, (ii) a relative low differential concentrations for $\mathrm{BOD}_{5}$ associated to

405 river self-cleaning potential for this compound as it was observed in a study dealing with 9 different

406 rainbow trout and carp farms in Poland (Teodorowicz 2013). On the contrary, Pulatsu et al (2004)

407 observed a significant impact of trout farming on the $\mathrm{BOD}_{5}$ concentration in the river. However, in this

408 study the downstream monitoring station was only at $100 \mathrm{~m}$ from the last farm investigated that might

409 not be enough distance for the river to clean itself or to reoxygenate as it was observed in other studies

410 (e.g. Boaventura et al. 1997; Teodorowicz 2013). Depending on river/farm flow and river characteristics,

411 a distance of 2-3 km downstream the fish farm is considered as being necessary to allow a self-purification

412 of the river regarding $\mathrm{BOD}_{5}$ (Boaventura et al. 1997).

413

414 Ammonium pattern through the river flow 
415 Slight variations were observed for $\mathrm{NH}_{4}-\mathrm{N}$ concentrations across the 4 fish farms inlets and therefore along

416 the river. However, upstream and downstream farms inlets (i.e. F1 and F4 respectively) were associated

417 to similar $\mathrm{NH}_{4}-\mathrm{N}$ mean concentrations of $0.08 \mathrm{mg} / \mathrm{L}$ (no significant differences between those two farms,

$418 \mathrm{P}$ value $>0.05$ ) (Figure $4 \mathrm{D}$ ). Thus, as for $\mathrm{BOD}_{5}$ parameter, we can assume that the distance between the

419 different farms in the present study was long enough to allow the river to purify itself regarding $\mathrm{NH}_{4}-\mathrm{N}$

420 and to get back to its initial background concentration. Therefore, there was not any impact of the fish

421 farms on the river quality in term of $\mathrm{NH}_{4}-\mathrm{N}$ concentrations. However a significant difference was observed

422 between $F 3$ and F4 for this parameters ( $P$ value $<0.01$ ) with a higher value at F4 inlet meaning that F3

423 might have had an impact on river quality for $\mathrm{NH}_{4}-\mathrm{N}$. The relative high average yearly production in $\mathrm{F} 3$ (i.e.

424165 tons, see Figure 1) associated to the relative short distance between those two farms (i.e. $500 \mathrm{~m}$, see

425 Figure 1) might explain this observation due to a limited self-cleaning potential by the river within this

426 relative short distance (Boaventura et al. 1997; Lalonde et al. 2015). Depending on farm production and

427 dry weather flow for the receiving water, Boaventura et al (1997) estimated at 3-12 km the distance

428 necessary for the river to get back to its initial organic chemical compound (including $\mathrm{NH}_{4}-\mathrm{N}$ )

429 concentration downstream from a given trout farm. With such low differential concentrations in F4 (0.08

$430 \pm 0.08 \mathrm{mgN} / \mathrm{L}, \mathrm{n}=41$, on average, see Figure $3 \mathrm{~F}$ ) and the self-cleaning potential of the river for this

431 compound (Boaventura et al. 1997; Lalonde et al. 2015), it appears very unlikely that this fish farm would

432 have any impact on the downstream river quality in term of $\mathrm{NH}_{4}-\mathrm{N}$ concentration.

\section{$434 \quad$ Nitrite pattern through the river flow}

435 A decrease in $\mathrm{NO}_{2}-\mathrm{N}$ concentrations was observed across the fish farm inlets and therefore along the river

436 (Figure $4 \mathrm{H}$ ). Median $\mathrm{NO}_{2}-\mathrm{N}$ concentration was revealed to be 0.06 and $0.03 \mathrm{mgN} / \mathrm{L}$ at the upstream (i.e.

437 F1 inlet) and downstream (i.e. F4 inlet) monitoring locations respectively. Therefore, considering this 
438 observation, the fish farm activity might have had a positive impact on the river quality regarding the $\mathrm{NO}_{2}^{-}$

$439 \mathrm{~N}$ concentration. To our knowledge, this potential "purification" of a river by trout farms regarding $\mathrm{NO}_{2}-$

$440 \mathrm{~N}$ was never observed in fish farms where no denitrification step is applied, as was the case for the

441 investigated fish farms in the present study where no water treatment processes were applied.

442 However, this result might be an artefact because as observed before most of the results obtained for F1

443 inlet location were below the LOQ of generally $0.06 \mathrm{mgN} / \mathrm{L}$. As mentioned above, in these cases, a value

444 equal to the LOQ was considered for the present study but the real values could have been lower. The

445 analytical LOQ was generally lower for F4 than for F1; this could explain why this "apparent dilution" of

446 the river by the farms effluent was obtained for this parameter. The relative small dataset for F1 $(n=17)$

447 compared to the other farms $(n=30-41)$ might also explain the differences observed between upstream

448 and downstream locations (i.e. F1 and F4 respectively). Other studies demonstrated the potential impact

449 of trout farming on $\mathrm{NO}_{2}-\mathrm{N}$ levels in river. Pulatsu et al (2004) observed a significant increase from 0.019

450 to $0.581 \mathrm{mgN} / \mathrm{L}$ from upstream to $100 \mathrm{~m}$ downstream from 5 different trout farms. This could confirm the

451 occurrence of an artefact with the results of the present study.

Total oxidized nitrogen pattern through the river flow

454

455

456

457

458

459

460

A slight increase was observed across the fish farms inlets and therefore along the river for TON with median concentrations of 1.4 and $1.8 \mathrm{mgN} / \mathrm{L}$ for the upstream (i.e. F1) and downstream (i.e. F4) locations respectively (Figure 4A). Therefore, fish farming might have a slight impact on the river quality considering this parameter and might be responsible for a release of $\mathrm{NO}_{3}-\mathrm{N}$ (not directly monitored). However, according to statistical analysis, no significant difference was observed between F1 and F4 inlets for this parameter average values ( $\mathrm{P}$ value $>0.05$ ). This result is in agreement with the literature on this topic; in another study, $\mathrm{NO}_{3}-\mathrm{N}$ mean concentrations were observed to increase from $0.13 \mathrm{mgN} / \mathrm{L}$ to $0.43 \mathrm{mgN} / \mathrm{L}$ 
461 from upstream to downstream of freshwater salmonids farms in Canada but no significant difference was

462 observed (Lalonde et al. 2015). In another study, a significant impact of trout farming on river quality for

463 both $\mathrm{NO}_{3}-\mathrm{N}$ and $\mathrm{NO}_{2}-\mathrm{N}$ was demonstrated (Pulatsu et al. 2004). Another study dealing with the potential

464 impact of 8 different trout farms in France demonstrated that there was no trend for $\mathrm{NO}_{3}-\mathrm{N}$ and that fish

465 farms could be either responsible of an increase or a decrease of $\mathrm{NO}_{3}-\mathrm{N}$ concentrations in the receiving 466 water (i.e. 100, 1000m downstream from the farms) (Guilpart et al. 2012).

\section{Orthophosphate pattern through the river flow}

Stable $\mathrm{PO}_{4}-\mathrm{P}$ concentrations were observed from $\mathrm{F} 1$ inlet to $\mathrm{F} 3$ inlet. Then, an increase was observed on $\mathrm{PO}_{4}-\mathrm{P}$ concentration from $0.01 \mathrm{mgP} / \mathrm{L}$ to almost $0.02 \mathrm{mgP} / \mathrm{L}$ between $\mathrm{F} 3$ and $\mathrm{F} 4$ inlets respectively (i.e. median values, see Figure $4 \mathrm{E}$ ). Therefore, and considering that there was not any other potentially polluting activity in the area (i.e. WWTP, agriculture), F3 had an impact on the river quality in term of $\mathrm{PO}_{4}-\mathrm{P}$ concentration. This was confirmed by the statistical analysis revealing that mean $\mathrm{PO}_{4}-\mathrm{P}$ inlet concentrations for $\mathrm{F} 3$ and $\mathrm{F} 4$ were significantly different $(\mathrm{P}$ value $<0.001)$ and that $\mathrm{PO}_{4}-\mathrm{P}$ concentrations were significantly higher at the $\mathrm{F} 4$ inlet than at $\mathrm{F} 3$ inlet. As for $\mathrm{NH}_{4}-\mathrm{N}$ this trend might be due to both a relative high production in $\mathrm{F} 3$ and short distance between $\mathrm{F} 3$ and $\mathrm{F} 4$. Considering similar $\mathrm{PO}_{4}-\mathrm{P}$ differential concentrations for $\mathrm{F} 3$ and $\mathrm{F} 4$ of about $0.02 \mathrm{mgP} / \mathrm{L}$ (see Figure 3D) and similar water uptake flow both farms, it is highly possible that an impact of F4 would have been observed if the river was monitored directly downstream from this fish farm. However, considering the self-cleaning potential of the river, the river might have got back to its $\mathrm{PO}_{4}-\mathrm{P}$ background concentration of about $0.01 \mathrm{mgP} / \mathrm{L}$ (see Figure $4 \mathrm{E}$ ) a few kilometres downstream from F4 (Boaventura et al. 1997). In another study, an impact of trout farming on total phosphorus (TP) on the river quality was observed with an increase from $0.069 \mathrm{mgP} / \mathrm{L}$ upstream to $0.117 \mathrm{mgP} / \mathrm{L}$ downstream from the fish farms (Pulatsu et al. 2004). It is assumed that this increase in 
484 TP is likely to be due to an increase in the reactive form, $\mathrm{PO}_{4}-\mathrm{P}$, which was the monitored parameter in 485 the present study.

486

Total suspended solids / turbidity patterns through the river flow

488

489

490

491

492

493

494

495

496

497

498

499

500

501

502

503

504

505

Slight TSS (and turbidity) increase were observed all along the river from $2 \mathrm{mg} / \mathrm{L}$ (2 NTU) to $3 \mathrm{mg} / \mathrm{L}$ ( 2.5 NTU) for upstream (i.e. F1 inlet) and downstream (i.e. F4 inlet) locations respectively (Figure 4F and 4C). This demonstrated that the 4 fish farms had a very limited impact on the river quality in term of TSS (and turbidity). This limited impact was confirmed by the statistical analysis that demonstrated that there was no significant differences between TSS and turbidity average values between F1 and F4 inlet values (P value $>0.05$ ). Considering relative low TSS and turbidity differential values observed for F4 (see Figure $3 E)$, it is unlikely that this fish farm would impact the downstream river quality for these parameters. This result is in agreement with the literature (Lalonde et al. 2015; Pulatsu et al. 2004) where a non-significant impact of trout farms on receiving water quality was observed for TSS.

\section{Temperature / pH patterns through the river flow}

No significant impact of fish farms on both river temperature and $\mathrm{pH}$ was observed in this study. This result is in agreement with Pulatsu et al (2004) who did not observe any impact of trout farms on the receiving water quality for these parameters.

\section{Seasonal variability (influent/effluent quality, impact)}

Differential values were gathered by season with no distinction between the different farms. The results are presented on the figure below (Figure 5). 
The results were compared statistically season by season in order to show any significant difference from one season to another for each parameter. Overall, except for $\mathrm{NH}_{4}-\mathrm{N}$ (Figure $5 \mathrm{C}$ ), no significant difference was observed between the average results obtained for each season for all the parameters monitored.

512 Even if differential values were on average higher in summer for TON, $\mathrm{NH}_{4}-\mathrm{N}, \mathrm{PO}_{4}-\mathrm{P}$ and $\mathrm{NO}_{2}-\mathrm{N}$, the statistical analysis revealed that no significant differences were observed with mean values calculated for the other seasons. The analysis of the results obtained for $\mathrm{NH}_{4}-\mathrm{N}$ revealed that mean values obtained for the spring season were significantly lower $(P$ value $<0.01)$ than the results obtained for any other season. No significant difference was observed when the other seasons were compared. These results demonstrate that season change had an overall limited impact on the polluting potential of the fish farms investigated and on the parameters monitored and that despite apparent higher differential values for nutrient during summer, fish farming was not significantly more impacting during this season than during any other seasons in terms of discharge. This observation is in agreement with another study where a negligible impact of season on 15 trout farms effluent quality was observed for all the parameters monitored except for TP (Lalonde et al. 2015). However, other studies demonstrated that the impact of trout farms on receiving water quality was higher in summer conditions when stocks are high, and both river flow and DO levels are low (Boyd \& Tucker 1998). In the future, climate change might increase the gap between winter and summer conditions with potential higher temperature/lower flows in rivers and more significant. 


\section{Conclusion}

530 A 10-year longitudinal survey (2005-2015) of the impact of 4 consecutive FT trout farms was performed

531 for the first time in Ireland based only on publically available and independently generated data analysis.

532 First, it was demonstrated that publically available data, although not always of very good quality, can be

533 used to reliably assess the impact of fish farming on receiving water quality. The impact of each farm on

534 water quality was assessed and it was demonstrated that the impact was significant for $\mathrm{NH}_{4}-\mathrm{N}$ and $\mathrm{DO}$

535 and more important for the farms which produced the most during the investigated period. Those results

536 were expected as regards to other studies performed on the impact of traditional trout production across

537 the world (Boaventura et al. 1997; Caramel et al. 2014; Garcia et al. 2014; Teodorowicz 2013). The

538 cumulative impact of the fish farms on receiving water quality was also assessed and it was demonstrated

539 that the distance between the different fish farms was globally sufficient to allow the river for self-

540 purification regarding the parameters analysed and no overall cumulative impact was observed for the

541 parameters considered. However, considering the relative high water volumes extracted by the studied

542 farm, an increase production would not be possible without the addition of water treatment technologies

543 to apply water reuse and therefore to reduce the demand on water without impacting receiving water

544 quality. The present study represents the first benchmarking of the freshwater fish farming industry in

545 Ireland and will be used as a baseline study, along with a study of the potential impacts on river's

546 hydromorphology, for comparison before the evolution through more advanced practices and the

547 expected implementation of water treatment processes in a near future due to the more and more

548 stringent legislative framework. However, the relevance of using the water quality parameters only can

549 be discussed. Indeed, notions such as the impact on biodiversity and ecotoxicology were not assessed in

550 the present study and will represent a challenge for future studies in order to take fully account of the

551 impact of the aquaculture industry as regards to the implication of the WFD and the expected future

552 intensification of the production. The present study will provide a basis for policy and commensurate 
553 decisions on future fish farm licencing and for meeting good quality status under WFD as it pertains to 554 operation of fish farming facilities.

555

556

557

558 
559

560

561

562

563

564

565

566

567

568

569

570

571

572

573

574

575

576

577

578

579

580

581

582

583

584

585

586

587

588

589

590

591

592

593

594

595

596

597

598

599

600

601

602

603

604

APHA. 2012. Standard methods for the examination of water and wastewater. In: Federation AWWAAPWAWE, editor: Eugene W. Rice, Rodger B. Baird, Andrew D. Eaton, Lenore S. Clesceri.

APHA. 2005. Standard methods for the examination of water and wastewater. In: Association APH, editor. Washington, DC.

Aubin J, Tocqueville A, and Kaushik S. 2011. Characterisation of waste output from flow-through trout farms in France: comparison of nutrient mass-balance modelling and hydrological methods. Aquatic Living Resources 24:63-70.

Boaventura R, Pedro AM, Coimbra J, and Lencastre E. 1997. Trout farm effluents: Characterization and impact on the receiving streams. Environmental Pollution 95:379-387. http://dx.doi.org/10.1016/S0269-7491(96)00117-0

Boyd C, and Tucker C. 1998. Pond Aquaculture Water Quality Management. Boston: Kluwer Academic Publishers. $p 700$.

Caramel B, Moraes M, Carmo C, Vaz-dos-Santos A, Tabata Y, Osti J, Ishikawa C, Cerqueira M, Mercante C, and (2014) Water Quality Assessment of a Trout Farming Effluent B, Brazil. , 6, 909-915. 2014. Water Quality Assessment of a Trout Farming Effluent, Bocaina, Brazil. Journal of Water Resource and Protection 6:909-915.

DAFM. 2015. National Strategic Plan for Sustainable Aquaculture. Irish department of agriculture, food and the marine.

Donnely N. 2011. Potential Diversification Opportunities for the Land-Based Aquaculture Sector in Northern Ireland European Union. p 144.

EC. 2000. Directive 2000/60/EC of the European Parliament and of the Council establishing a framework for the Community action in the field of water policy. In: Commission E, editor.

EEC. 1978. Council Directive 78/659/EEC of 18 July 1978 on the quality of fresh waters needing protection or improvement in order to support fish life - Repealed by Directive 2006/44/EC. In: Union CotE, editor. 78/659/EEC.

Emerson K, Russo RC, Lund RE, and Thurston RV. 1975. Aqueous Ammonia Equilibrium Calculations: Effect of $\mathrm{pH}$ and Temperature. Journal of the Fisheries Research Board of Canada 32:2379-2383. 10.1139/f75-274

Garcia F, Kimpara JM, Valenti WC, and Ambrosio LA. 2014. Emergy assessment of tilapia cage farming in a hydroelectric reservoir. Ecological Engineering 68:72-79. http://dx.doi.org/10.1016/j.ecoleng.2014.03.076

Guilpart A, Roussel J-M, Aubin J, Caquet T, Marle M, and Le Bris H. 2012. The use of benthic invertebrate community and water quality analyses to assess ecological consequences of fish farm effluents in rivers. Ecological Indicators 23:356-365. http://dx.doi.org/10.1016/j.ecolind.2012.04.019

Hennessy MM, Wilson L, Struthers W, and Kelly LA. 1996. Waste loadings from two freshwater Atlantic Salmon Juvenile farms in Scotland. Water, Air, and Soil Pollution 86:235-249. 10.1007/BF00279159

Hornund RW, and Reed LD. 1990. Estimation of average concentration in the presence of nondetectable values. AApplied Occupational and Environmental Hygiene 5.

Jokumsen A, and Svendsen LM. 2010. Farming of Freshwater rainbow trout in Denmark Technical University of Denmark, National Institute of Aquatic Resources, DTU Aqua p50.

Kırkağaç MU, Pulatsu S, and Topcu A. 2009. Trout Farm Effluent Effects on Water Sediment Quality and Benthos. Clean Soil Air Water 37.

Koçer MAT, Kanyılmaz M, Yılayaz A, and Sevgili H. 2013. Waste loading into a regulated stream from landbased trout farms. Aquaculture Environment Interactions 3:187-195. 
605

606

607

608

609

610

611

612

613

614

615

616

617

618

619

620

621

622

623

624

625

626

627

628

629

630

631

632

633

634

635

636

637

638

639

640

641

642

643

644

645

646

647

648

649

650

651

Krause G, Brugere C, Diedrich A, Ebeling MW, Ferse SCA, Mikkelsen E, Pérez Agúndez JA, Stead SM, Stybel $\mathrm{N}$, and Troell M. 2015. A revolution without people? Closing the people-policy gap in aquaculture development. Aquaculture. 10.1016/j.aquaculture.2015.02.009

Lalonde BA, Ernst W, and Garron C. 2015. Chemical and physical characterisation of effluents from landbased fish farms in Atlantic Canada. Aquaculture International 23:535-546. 10.1007/s10499-0149834-y

Lazzari R, and Baldisserotto B. 2008. Nitrogen and phosphorus waste in fish farming. Boletim do Instituto de Pesca 34:591-600.

Martins CIM, Eding EH, Verdegem MCJ, Heinsbroek LTN, Schneider O, Blancheton JP, d'Orbcastel ER, and Verreth JAJ. 2010. New developments in recirculating aquaculture systems in Europe: A perspective on environmental sustainability. Aquacultural Engineering 43:83-93. 10.1016/j.aquaeng.2010.09.002

Neto RM, Nocko HR, and Ostrensky A. 2015. Environmental characterization and impacts of fish farming in the cascade reservoirs of the Paranapanema River, Brazil. Aquaculture Environment Interactions 6:255-272.

Noroozrajabi A, Ghorbani R, Abdi O, and Nabavi E. 2013. The Impact of Rainbow Trout Farm Effluents on Water Physicochemical Properties of Daryasar Stream. World Journal of Fish and Marine Sciences 5:342-346.

Papatryphon E, Petit J, Van Der Werf H, Kaushik S, and Claver K. 2005. Nutrient-Balance Modeling as a Tool for Environmental Management in Aquaculture: The Case of Trout Farming in France. Environmental Management 35:161-174.

Pulatsu S, Rad F, Köksal G, Aydın F, Benli AÇK, and Topçu A. 2004. The Impact of Rainbow Trout Farm Effluents on Water Quality of Karasu Stream, Turkey. Turkish Journal of Fisheries and Aquatic Sciences 4:9-15.

Sindilariu PD, Brinker A, and Reiter R. 2009. Factors influencing the efficiency of constructed wetlands used for the treatment of intensive trout farm effluent. Ecological Engineering 35:711-722. 10.1016/j.ecoleng.2008.11.007

Sturrock H, Newton R, Paffrath S, Bostock J, Muir J, Young J, Immink A, and Dickson M. 2008. Prospective analysis of the aquaculture sector in the EU - Part 2: Characterisation of emerging aquaculture systems. In: (IPTS) IP, editor: JRC - European Commission.

Teodorowicz M. 2013. Surface water quality and intensive fish culture. Archives of Polish Fisheries. p 65.

Tomasso JR. 1994. Toxicity of nitrogenous wastes to aquaculture animals. Reviews in Fisheries Science 2:291-314. 10.1080/10641269409388560

True B, Johnson W, and Chen S. 2004. Reducing phosphorus discharge from flow-through aquaculture I: facility and effluent characterization. Aquacultural Engineering 32:129-144. http://dx.doi.org/10.1016/j.aquaeng.2004.08.001

USEPA. 2003. Methods of Dealing with Values Below the Limit of Detection using SAS. In: Croghan CW, and Egeghy PP, editors.

Verdegem MCJ. 2013. Nutrient discharge from aquaculture operations in function of system design and production environment. . Rev Aquacult 5:158-171.

Všetičková L, Adamek Z, Rozkošný M, and Sedláček P. 2012. Effects of semi-intensive carp pond farming on discharged water quality. . Acta Ichthyologica Et Piscatoria 42.

Yalcuk A, Pakdil N, Kantürer, and O. 2014. Investigation of the Effects of Fish Farms in Bolu (Turkey) on Aquatic Pollution. . International Journal of Agricultural and Food Research 3.

Živić I, Marković Z, Filipović-Rojka Z, and Živić M. 2009. Influence of a Trout Farm on Water Quality and Macrozoobenthos Communities of the Receiving Stream (Trešnjica River, Serbia). International Review of Hydrobiology 94:673-687. 


\section{Figure 1}

Schematic representation of the river, the 4 studied fish farms and of the associated monitoring points (inlets and outlets). The main characteristics of each farm is also presented.

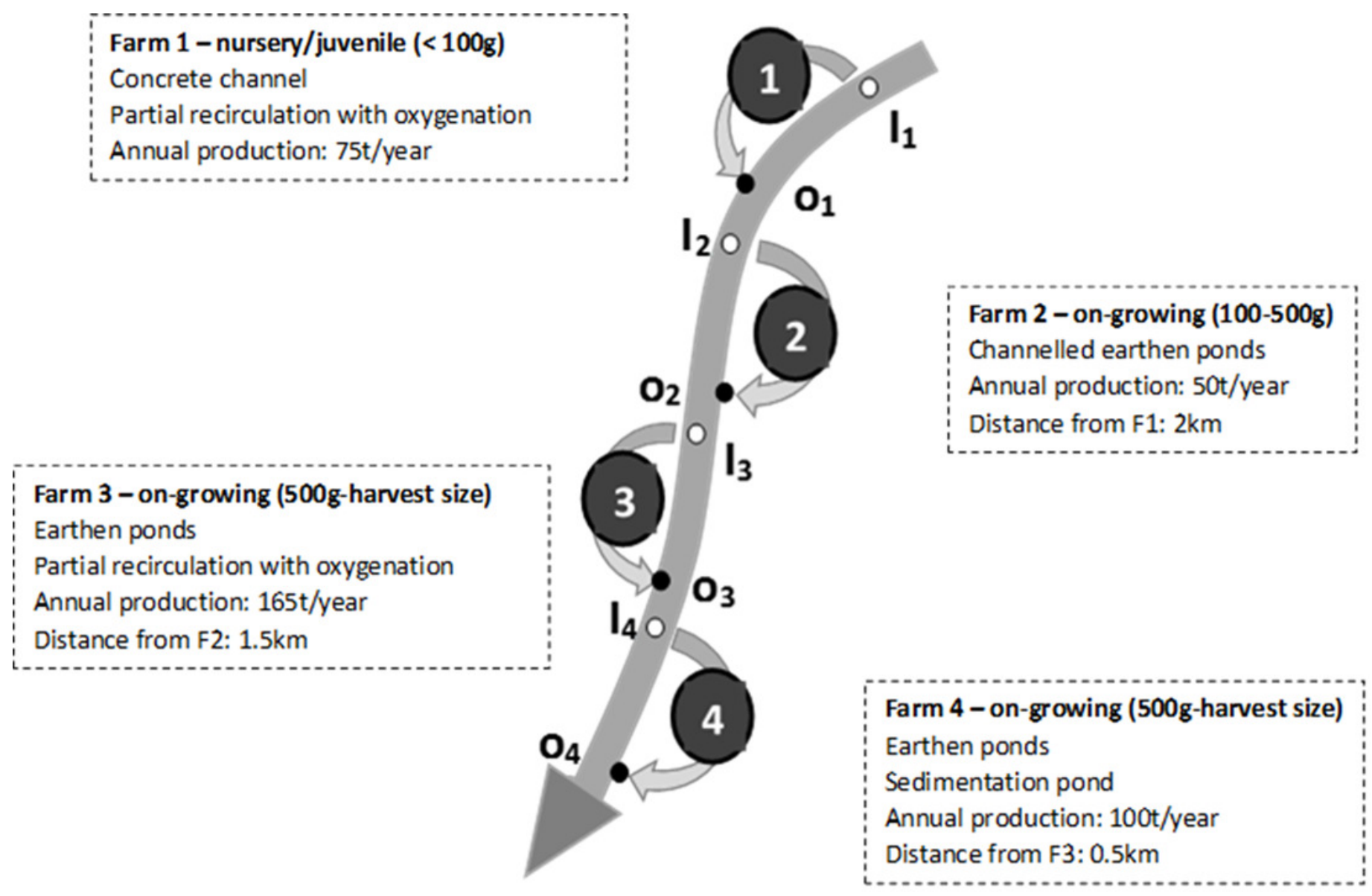


Figure 2

Box-plot global representation of inlet and outlet values compiled and gathered for the 4 fish farms and for all the monitored parameters (2005-2015). 


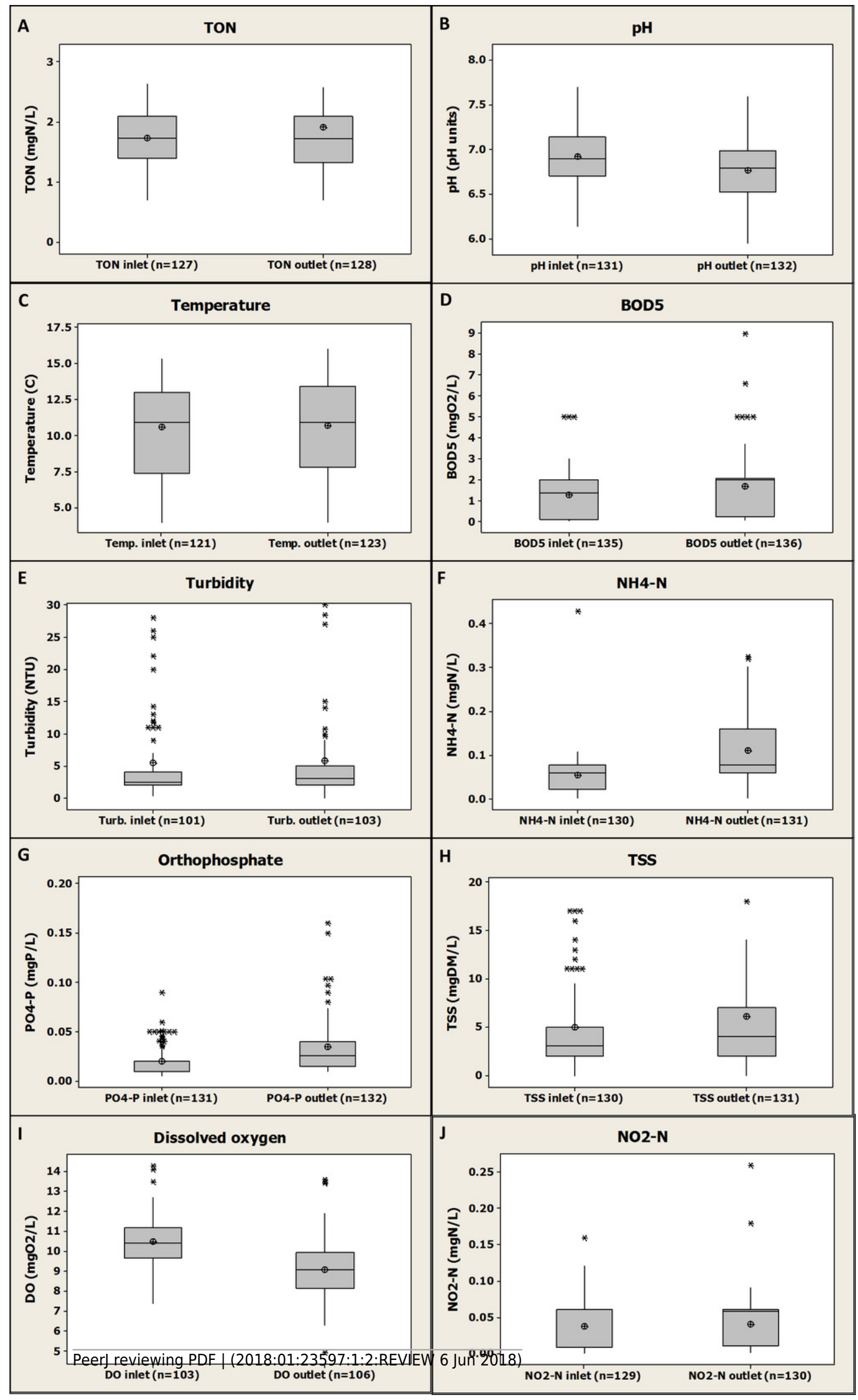




\section{Figure 3}

Box-plot representation of the differential concentrations $\left(D_{i}\right)$ between inlet and outlet of each of the 4 fish farms and for each regulated parameter (2005-2015).

$1,2,3$ and 4 represent the consecutive fish farms in the order of the river flow direction. In brackets, the discharge licence limit value for each regulated parameter as mentioned in the

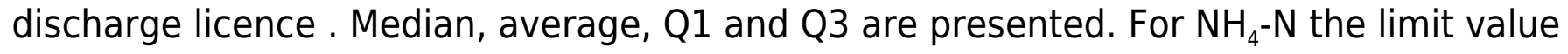
associated is for total ammonia (TAN) 


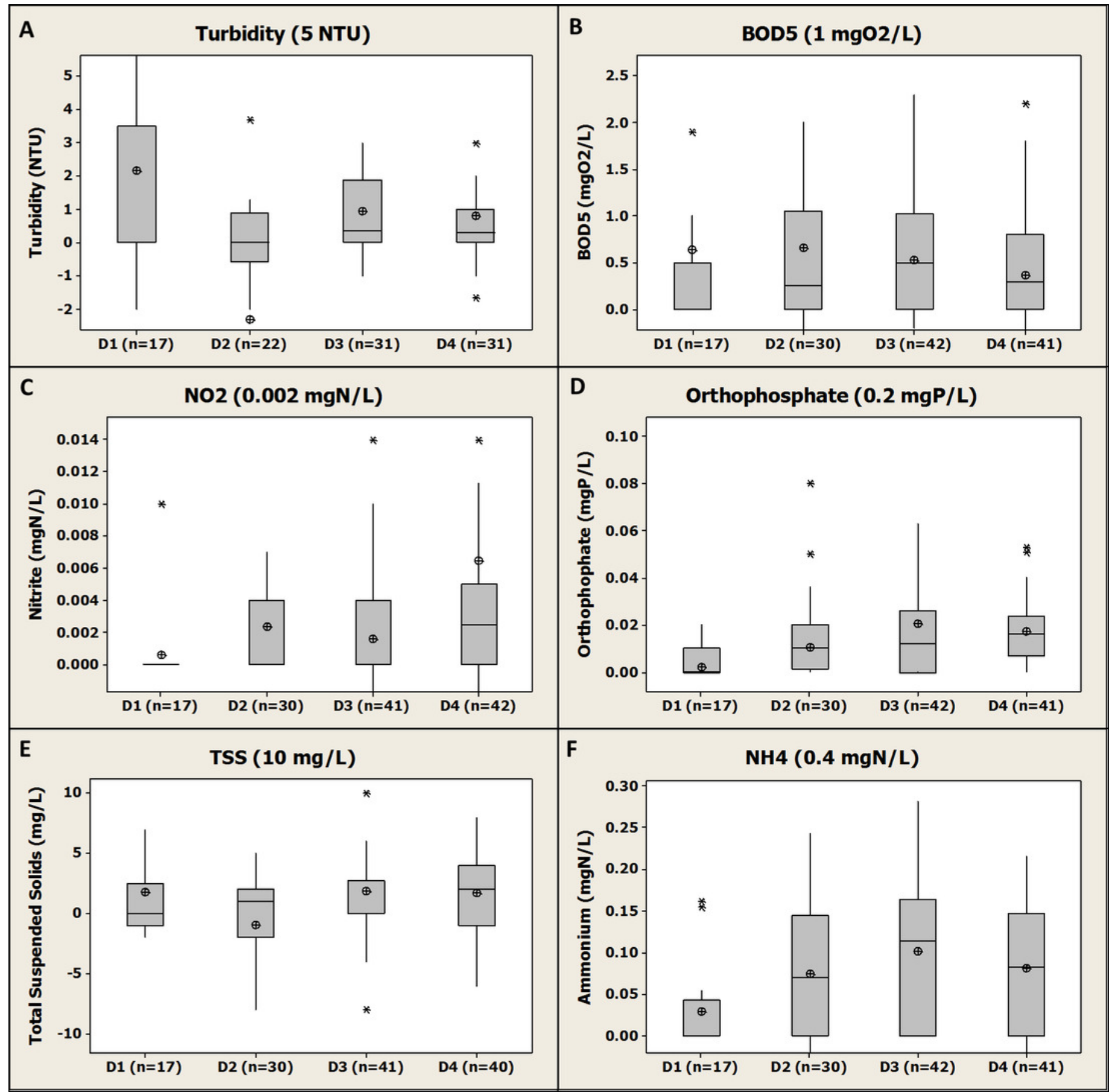




\section{Figure 4}

Box-plot representation of the water quality evolution through the 4 different fish farms inlets showing the cumulative impact of the fish farms on river quality for the monitored parameters.

1, 2, 3 and 4 represent the consecutive farms in the order of the river flow. Median, average, Q1 and Q3 are presented. 


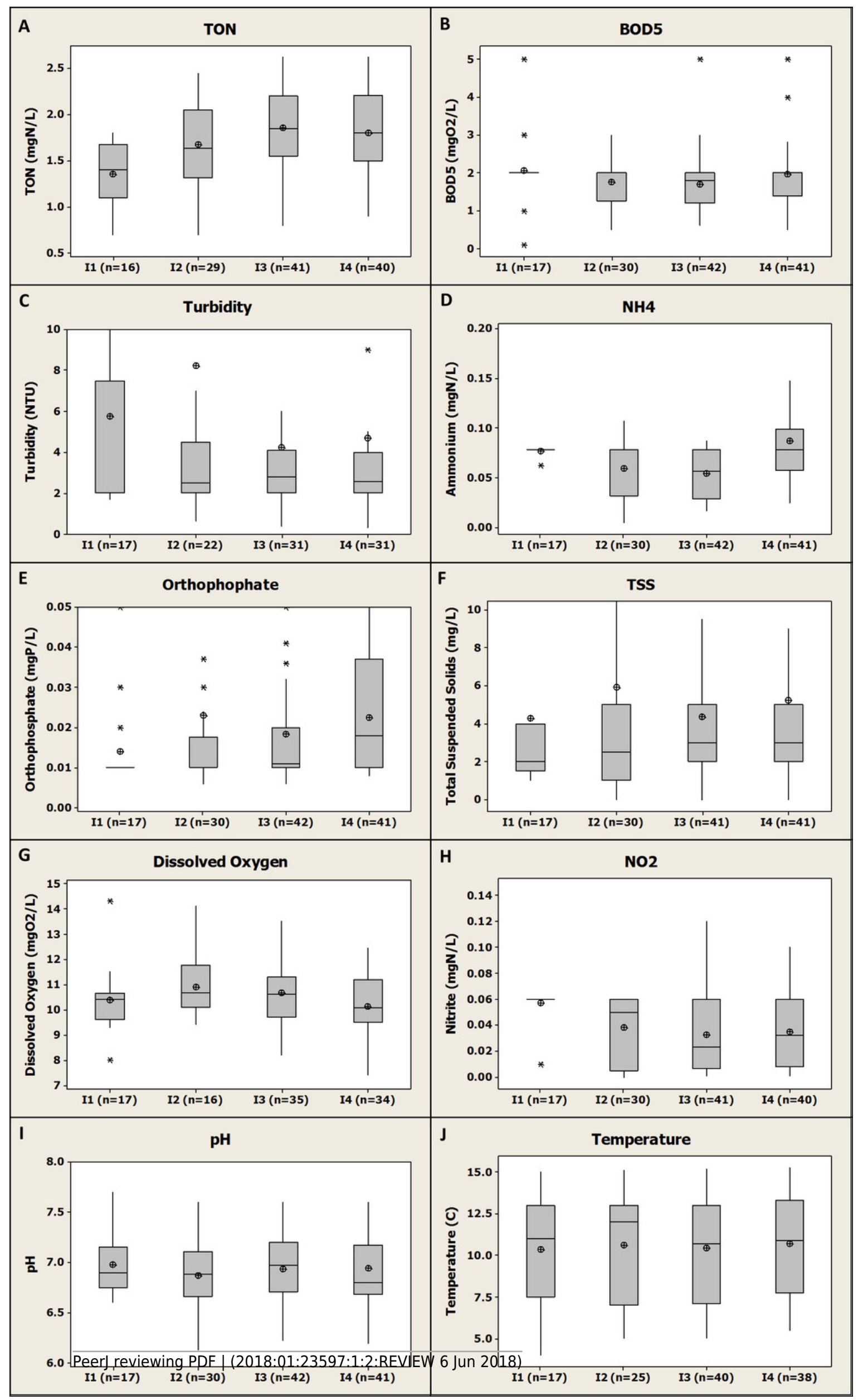


Figure 5

Box-plot representation of the seasonal variation of the differential values compiled and gathered for the 4 fish farms for the monitored parameters.

Median, average, Q1 and Q3 are presented 


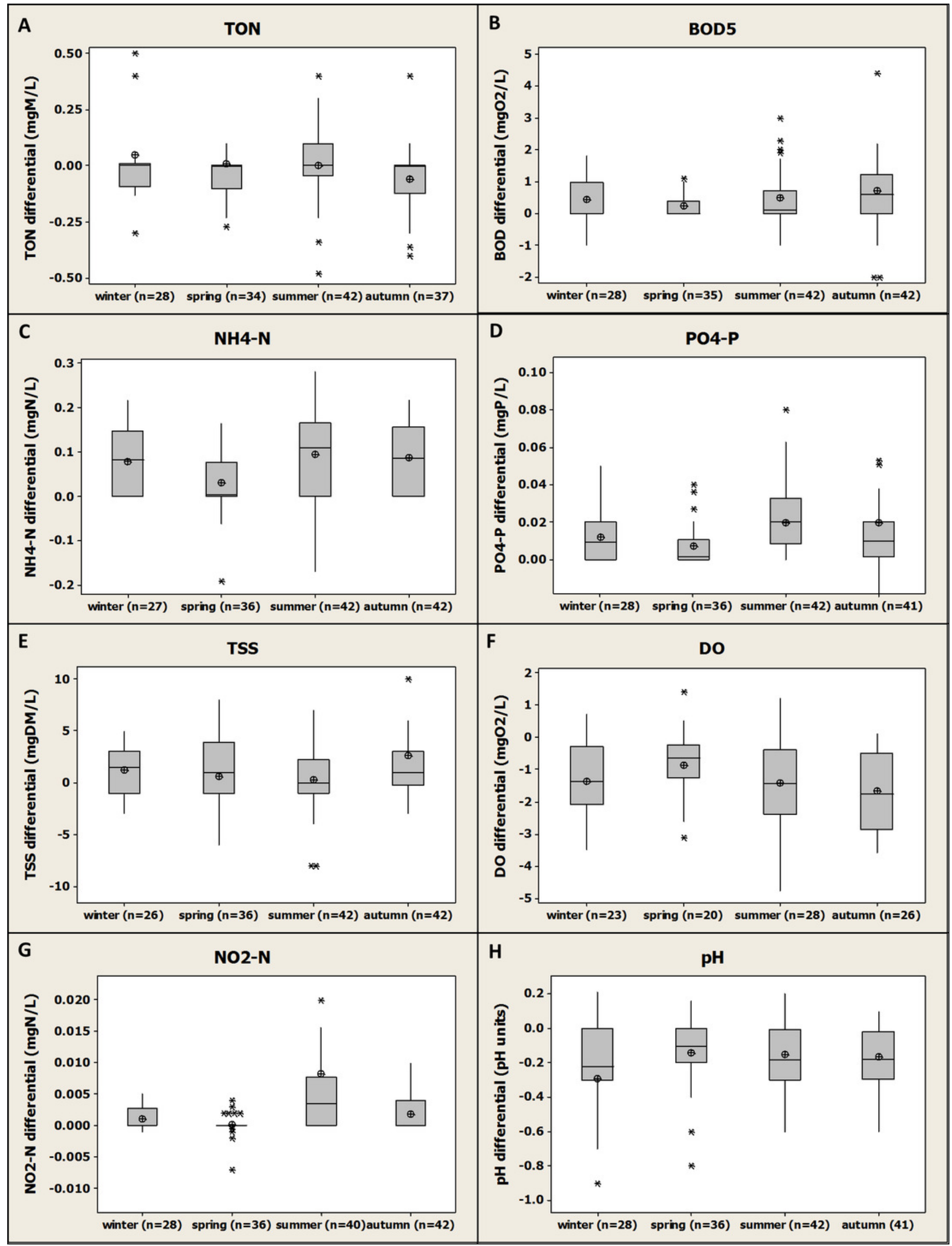

